\title{
Ecos do fim do mundo em três perspectivas
}

\author{
Maria da Conceição Almeida' \\ https://orcid.org/0000-0003-1850-5288
}

\section{Fagner Torres de França'}

https://orcid.org/0000-0003-2170-4288

I - Universidade Federal do Rio Grande do Norte. NATAL (RN), Brasil.

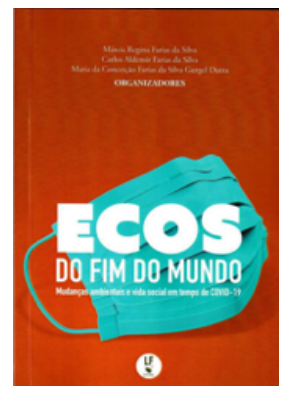

FARIAS DA SILVA, M.R. et al. (org.).

Ecos do fim do mundo. Mudanças

ambientais e vida social em tempo de

COVID-19. São Paulo: LF editorial, 2020.

Resumo: O presente texto apresenta o livro Ecos do fim do mundo. Mudanças ambientais e vida social em tempo de COVID-19, publicado em 2020 pela Livraria da Física e organizado por Márcia Maria Regina da Silva (UERN), Carlos Aldemir Farias da Silva (UFPA) e Maria da Conceição Farias da Silva Gurgel Dutra (UFPB). Por meio do método da sociologia do presente, desenvolvido pelo pensador francês Edgar Morin, a obra, de caráter transdisciplinar, busca mapear as diversas faces da atual pandemia em uma abordagem teórico-empírica a partir do olhar de vinte e dois pesquisadores em vinte e seis artigos, que acompanham de perto o desenrolar da pandemia em suas mais diversas consequências.

Palavras-chaves: pandemia; sociologia do presente; transdisciplinaridade.

Abstract: Ecoes of the end of the world in three perspectives - This text presents the book Echoes of the end of the world. Environmental changes and social life in the time of COVID-19, published in 2020 by Livraria da Física and 
organized by Márcia Maria Regina da Silva (UERN), Carlos Aldemir Farias da Silva (UFPA) and Maria da Conceição Farias da Silva Gurgel Dutra (UFPB ). Through the method of the sociology of the present, developed by the french thinker Edgar Morin, the work, with a transdisciplinary character, seeks to map the different faces of the current pandemic in a theoretical-empirical approach from the perspective of 22 researchers in 26 articles, which closely examines the development of the pandemic in its most diverse consequences.

Keywords: pandemic; sociology of the present; transdisciplinarity.

Vieram de longe os ecos do fim do mundo. Tão distantes que apenas com muito silêncio era possível ouvi-los. As mãos coladas à cabeça fazendo uma espécie de concha para ampliar a audição. Os ruídos chegavam desencontrados, inofensivos, às vezes até mesmo engraçados. Em alguns lugares, foi a alegria do carnaval. Um folião de traços asiáticos, fotografado em um bloco no Rio de Janeiro, usava máscara cirúrgica e uma camisa amarela onde aparecia escrito "Corona”, uma conhecida marca de cerveja.

Os rumores eram divertidos, motivos de chacota. Até que foram se aproximando e, poucos dias depois, em vez do riso, trouxeram o medo. O novo coronavírus provavelmente já circulava no Brasil durante a festa de Momo, invisível e ameaçador. Foi descoberto em 31 de dezembro de 2019 na cidade de Wuhan, na China. A redução do espaço-tempo, característica da modernidade, fez com que rapidamente o vírus se espalhasse por todo o globo terrestre, de Moscou a Mossoró, do Tennessee, EUA, a Tenente Ananias, Rio Grande do Norte, Brasil. Livros e filmes de anos anteriores pareciam já profetizar com alta fidelidade o planeta assolado por pandemias.

Isso nos lembra as sábias palavras do escritor Daniel Munduruku no texto de abertura do livro Ecos do fim do mundo. Mudanças ambientais e vida social em tempo de COVID-19, organizado por Márcia Regina Farias da Silva1', Carlos Aldemir Farias da Silva² e Maria da Conceição Farias da Silva Gurgel Dutra ${ }^{3}$. No artigo intitulado Para além da pandemia, diz Munduruku:

Quando falamos em profecias, normalmente estamos pensando que alguém previu algo para o futuro. Quase nunca passa pela cabeça das pessoas que "prever" o futuro é a coisa mais simples do mundo: o futuro se escreve no presente. Trata-se puramente da observação da natureza (MUNDURUKU, 2020, p. 19).

\footnotetext{
1 Professora Doutora, Universidade Estadual do Rio Grande do Norte.

2 Professor Doutor, Universidade Federal do Pará.

3 Professora Doutora, Universidade Federal da Paraíba.
} 
Voilà! Não podia ser mais simples e direto. Vivemos presos e paralisados entre nostalgias, utopias e distopias. Mas parece que nunca temos olhos para explorar as muitas virtualidades do presente. É o único tempo que, de fato, temos e ao qual pertencemos. O tempo não é dinheiro, como diz o velho adágio, mas o tecido mesmo da vida. Projetamos o futuro a partir das possibilidades abertas no presente. É justamente nesse terreno em que se inscreve Ecos do fim do mundo - coletânea de vinte e dois textos escritos por vinte e seis pesquisadores — publicado em 2020 pela editora Livraria da Física.

A obra, de 225 páginas, é dividida em duas partes. A primeira chama-se Ciência e pandemia, com artigos científicos de professores e alunos de pós-graduação de seis universidades públicas brasileiras localizadas no Norte e no Nordeste do país (UERN, UFERSA, UFRN, UFPB, UFCG e UFPA), "que problematizam o valor da vida e dos direitos dos cidadãos perante o Estado" (p. 14), como afirmam os organizadores na Apresentação. A segunda parte, Geografia e meio ambiente, apresenta artigos de opinião escritos por mestrandos em Geografia da Universidade do Estado do Rio Grande do Norte (UERN), como resultado da disciplina "Geografia e meio ambiente" e do projeto de extensão "Conhecer para combater: produção de conteúdos sobre a relação ambiente-sociedade e a pandemia da COVID-19".

Desde que chegou e se acomodou no presente, a pandemia foi objeto de inúmeros livros, artigos e ensaios dos mais renomados pensadores. Se jogarmos a palavra "pandemia" na ferramenta de busca da loja virtual Amazon, por exemplo, receberemos um sem número de resultados relacionados ao tema. O capital, sim, não perde tempo. Portanto, qual a originalidade da presente obra em meio a tudo o que já foi escrito no mundo sobre a nova pandemia? Para nós, a obra Ecos do fim do mundo se afirma como trabalho inédito e de fundamental importância a partir de três pontos principais.

Em primeiro lugar, podemos destacar a ousadia dos professores e alunos em trabalhar suas reflexões a partir do resgate da chamada sociologia do presente, desenvolvida pelo pensador francês Edgar Morin entre meados dos anos 1940 até aproximadamente 1970. Trata-se de uma retomada necessária de um método de abordagem multidimensional dos fenômenos sociais praticamente esquecido, trabalhado hoje por muito poucos autores nas ciências humanas, em geral devido à fragmentação do conhecimento e à incapacidade de se pensar de forma integrada - embora, sejamos justos, os novos regimes de historicidade tenham buscado fazer do presente um campo fértil a ser explorado. 
O terreno do presente é minado e perigoso, pois habitado fortemente pelo princípio da incerteza, pelas forças de incompletude e de imprevisibilidade que contraditoriamente nos recusamos a perceber, mas que também abrem brechas nas quais o novo pode nascer. Um texto escrito no calor do momento pode cair no ostracismo dias ou meses depois, quando as configurações que deram origem a ele mudaram completamente e as "previsões" do(a) pesquisador(a) mostraram-se frágeis e de pouco alcance explicativo. Mais uma vez, o problema é não saber reconhecer no presente as forças de determinação e indeterminação que operam aqui-agora. Por isso dizemos ser um trabalho arriscado, que poucos se aventuram a fazer.

A sociologia do presente de Edgar Morin tem por base os conceitos recursivos de acontecimento, crise e fenômeno. No caso do novo coronavírus, temos um acontecimento de natureza ao mesmo tempo antrópica e biológica, capaz de liberar uma policrise sanitária, humanitária, política, econômica e social. Tais crises só podem ser estudadas de maneira integrada a partir de uma observação fenomenográfica transdisciplinar, materializada em relatos densos, frutos de uma observação cuidadosa simultaneamente panorâmica e singular, pois as dinâmicas do vírus são diferentes e dependentes de uma série de fatores. Por isso o pesquisador deve estar atento ao detalhe revelador.

De certa forma, o acontecimento, aqui, é também aquilo que se tira da invisibilidade e se faz emergir, caso contrário permaneceria não percebido. Essa pode ser uma das explicações para a onda de negacionismo que percorre o mundo: continuar a negar como não existente aquilo que foi tornado óbvio, retirado do oblívio.

Em segundo lugar, os autores do livro falam a partir do espaço onde produzem conhecimento. Portanto, pensam a pandemia a partir do interior das universidades públicas e em sua interface com a sociedade, por meio da tríade ensino, pesquisa e extensão. Ao cartografar o terreno do presente, os pesquisadores identificaram, por exemplo, a massa enorme de informações falsas poluindo o meio ambiente informacional, prejudicando os esforços dos profissionais da saúde e dos governos estaduais e municipais em combater o problema. Nas palavras dos organizadores,

Um fator que chama a atenção é o grande volume de recomendações errôneas sobre os modos de prevenção à COVID-19. As sugestões vão desde a indicação de medicamentos sem comprovação de sua eficácia, uso de vitaminas $C$ e $D$, até gargarejos de diversas ervas. Ao 
considerarmos a velocidade da dispersão de informações equivocadas e sem comprovação científica sobre a doença, é possível inferir que elas trazem preocupação aos profissionais da saúde, gestores públicos e pesquisadores, que se dedicam a combater e a estudar as ações de combate à pandemia. (SILVA et al., 2020, p. 15).

Tal preocupação expande os horizontes da geografia para além dos limites disciplinares, de alguma forma borrando as fronteiras e forçando o diálogo para a resolução de um problema comum a todas as áreas do conhecimento. Estamos falando de uma hibridação entre a geografia da fome, a geografia humana, a geografia política etc., em diálogo com outras áreas de conhecimento como a saúde, a sociologia, a história, a economia.

Os vinte e dois textos de Ecos do fim do mundo tratam do cruzamento dos diversos aspectos da pandemia, mas concordam em pelo menos cinco pontos essenciais: a pandemia desorganizou nossas certezas e comportamentos sociais; nada será como antes; não sabemos o que nos aguarda; precisamos integrar os saberes para um agir mais ético e complexo em prol da humanidade; estamos todos na mesma comunidade de destino e precisamos aprender a pensar dessa forma. Ou seja, o que se passa na China ou no Brasil deixa de ser um problema doméstico para expandir seus efeitos por todo o planeta, seja por causa de um vírus, seja por causa das queimadas na floresta amazônica.

Finalmente, em terceiro lugar, o livro é generoso não apenas com os leitores, mas também com os autores, em sua maioria mestrandos em geografia da UERN, que exercitaram, em um momento crucial para o século XXI, de forma intensa, in vivo (e não in vitro, ou seja, no laboratório), um amplo trabalho de observação, apontamentos, descrição e reflexão, princípios também fundamentais para a sociologia do presente. Os organizadores e proponentes da obra sabem: é justamente assim, no ramerrão do campo de trabalho e do chão de fábrica diário, que se forma um intelectual.

Realizar uma pesquisa com base na sociologia do presente exige coragem: coragem de não saber a verdade definitiva sobre nada e mesmo assim arriscar-se; coragem para enfrentar os imponderáveis da vida e do trabalho de campo; coragem frente às incertezas do momento, das interpretações sempre parciais e potencialmente perecíveis dos fenômenos sociais. Em um momento em que as universidades e a ciência estão no alvo dos movimentos conservadores, não podemos descuidar da formação de um espírito científico ético, rigoroso e engajado com a vida. 
Ecos do fim do mundo. Mudanças ambientais e vida social em tempo de COVID-19 é recomendado para todos aqueles que querem entender mais profundamente a crise sanitária, social, política e econômica pela qual passamos por meio de um olhar diversificado e comprometido com o rigor de uma ciência transdisciplinar.

Maria da Conceição Almeida é antropóloga e professora titular do departamento de Fundamentos e Políticas da Educação do Centro de Educação da Universidade Federal do Rio Grande do Norte. É doutora em Ciências Sociais pela Pontifícia Universidade Católica de São Paulo-SP. É coordenadora do Grupo de Estudos da Complexidade - GRECOM, membro da Association International pour la Pensée Complexe - Paris, do Conselho Científico Internacional da Multiversidad Mundo Real Edgar Morin (Hermosillo - México), do Conselho da Cátedra para la Transdisiplinaridad (Valladolid - Espanha) e coordenadora, pelo Grecom/UFRN, do primeiro ponto brasileiro da Cátedra Itinerante Unesco Edgar Morin - CIUEM, com sede em Buenos Aires, Argentina.

calmeida17@hotmail.com

Fagner Torres de França é jornalista e doutor em Ciências Sociais pela UFRN.

fagnertf@yahoo.com.br

Contribuição de cada co-autor: ambos leram o livro e realizaram a escrita.

\section{Referências}

MUNDURUKU, D. Para além da pandemia. In: SILVA, M. R. F.; SILVA, C. A. F.; DUTRA, M. C. F. S. G. (Orgs.). Ecos do fim do mundo. Mudanças ambientais e vida social em tempo de COVID-19. São Paulo: Livraria da Física, 2020. p. 19-21.

SILVA, M. R. F.; SILVA, C. A. F.; DUTRA, M. C. F. S. G. (Orgs.). Ecos do fim do mundo. Mudanças ambientais e vida social em tempo de COVID-19. São Paulo: Livraria da Física, 2020.

Resenha recebida em 16/09/2020 e aprovada em 15/01/2021. 